\title{
A CRIAÇÃO DE UMA HISTÓRIA INFANTIL TÁTIL SOBRE A DOENÇA COVID-ıو EM MEIO À PANDEMIA: UMA AÇÃO LITERÁRIA INCLUSIVA
}

\author{
THE CREATION OF A TACTILE CHILDREN'S STORY ABOUT COVID-r9 DISEASE IN \\ THE MIDST OF THE PANDEMIC: AN INCLUSIVE LITERARY ACTION
}

\author{
Cristina Silva Ribeiro de Souza ${ }^{1}$
}

RESUMO: O propósito do estudo aqui apresentado é o de analisar e compartilhar as possibilidades e contribuições que as histórias infantis táteis podem promover ao pequeno leitor com deficiência visual (DV). A partir dessa concepção cabe uma reflexão sobre as estratégias que podemos desenvolver de forma enriquecedora a fim de possibilitar a criança cega uma vivência mais significativa e concreta a partir das ilustrações que compõem uma história. Pode-se afirmar que o livro objeto aqui apresentado potencializa a participação e interação dos alunos com deficiência visual promovendo a inclusão de todos os envolvidos no processo educativo.

Palavras-chave: História Infantil tátil. Deficiência Visual. Pandemia. Covid-ıg.

ABSTRACT: The purpose of the study presented here is to analyze and share the possibilities and contributions that tactile children's stories can promote to the visually impaired reader (VI). From this conception there is a reflection on the strategies that we can develop in an enriching way in order to enable the blind child a more meaningful and concrete experience from the illustrations that make up a story. It can be said that the book object here presented potentiates the participation and interaction of students with visual disability promoting the inclusion of all those involved in the educational process.

Keywords: Tactile Children's History. Visual Impairment.Pandemic.Covid-I9.

\section{INTRODUÇÃO}

Em tempos tão desafiadores em meio a uma pandemia causada pela Covid-ı, esta doença chega inesperadamente provocando um grande impacto mundial. Segundo

\footnotetext{
${ }^{I}$ Professora, artesã, autora de livros táteis, pesquisadora. Mestra em Diversidade e Inclusão pela Universidade Federal Fluminense- UFF. Especialização em Psicomotricidade pela Universidade Cândido Mendes / AVM. Graduada em Pedagogia pelo Instituto Isabel Faculdade de Ciências Humanas e Sociais. Integra o quadro de docentes da equipe de Educação Infantil do Instituto Benjamin Constant.
} 
informações da Organização Mundial de Saúde (2021), o surgimento da Covid-ı9, doença causada pelo novo coronavírus SARS-COV-2, teve seu início na China em dezembro de 2019, onde se desdobrou em uma propagação por todo o mundo. Por conta disso, o isolamento social imediato foi uma das recomendações para a prevenção da proliferação da doença.

O impacto gerou muitas alterações na vida social das pessoas paralisando a economia do país e as práticas habituais da população no geral. Como medida e estratégia de prevenção da disseminação da doença, o isolamento social foi extremamente necessário. Segundo Ministério da Saúde (BRASIL, 202I),

Limitar o contato próximo entre pessoas infectadas e outras pessoas é importante
para reduzir as chances do SARS-CoV-2. Principalmente durante a pandemia,
devem ser adotados procedimentos que permitam reduzir a interação entre as
pessoas com o objetivo de diminuir a velocidade de transmissão do vírus.
(BRASIL, 202I)

Para tanto as medidas de prevenção, o isolamento, o distanciamento, a quarentena e o então fechamento das escolas públicas e privadas, infelizmente, foi inevitável. Diante a este cenário controverso, como fazer com que a criança compreenda esse momento tão catastrófico.

Pensando em desenhar um percurso a fim de suavizar esse caos e contribuir com uma ação educativa, este trabalho buscou então, estudar as contribuições que as histórias infantis podem promover dentro do contexto de uma pandemia, a partir de uma narrativa com uma linguagem clara, lúdica, mágica, sensorial e assim contribuir com informações que chegue á criança, mesmo que distante da escola. Sobre isso, os estudos realizados por MENEZES ET AL., (2020), apontam as contribuições da contação de histórias para a saúde mental no contexto da pandemia de Covid-r9. Os mesmos autores destacam que a literatura infantil possibilita que várias reflexões sobre temas sociais sejam abordadas de um modo mais lúdico, poético e questionador. Além do que, as histórias estão muito presentes no cotidiano de todo sujeito, onde as pessoas carecem serem ouvidas e compreendidas através de seus relatos e vivências,

O ato de ouvir e contar histórias está, quase sempre, presente nas nossas vidas: desde que nascemos, aprendemos por meio das experiências concretas das quais participamos, mas também através daquelas experiências das quais tomamos conhecimento através dos que os outros nos contam. Todos temos necessidade de 
contar aquilo que vivenciamos, sentimos, pensamos, sonhamos. Dessa necessidade humana surgiu a literatura: do desejo de ouvir e contar para, através desta prática, compartilhar (KAERCHER, 2001, p. 83).

A partir das histórias as crianças conseguem associar o que escutam com a realidade, fomentam o imaginário e dessa forma desenvolvem maneiras de lidar com as emoções, desafios e conflitos. De acordo com ABRAMOVICH (1995),

Ler histórias para crianças, sempre, sempre...É também suscitar o imaginário, é ter a curiosidade respondida em relação a tantas perguntas, é encontrar outras ideias para solucionar questões (como as personagens fizeram...). É uma possibilidade de descobrir o mundo imenso dos conflitos, dos impasses, das soluções que todos vivemos e atravessamos - dum jeito ou de outro - através dos problemas que vão sendo defrontados, enfrentados (ou não), resolvidos (ou não) pelas personagens, de cada história (cada uma a seu modo). (ABRAMOVICH, I995, p.17).

O livro infantil é um objeto/brinquedo que encanta a criança e quanto a isto sabemos que o imaginário favorece para a construção de conhecimentos, além do que, contribui na formação de todo sujeito e quando se aprende por intermédio das histórias o aprendizado adquirido perdura (GARCIA, et.al. 2003). Para tanto é importante lembrar que o livro infantil precisa estar ao alcance das mãos de todo pequeno leitor.

A partir desta apreciação, no que concerne à inclusão, e para o estudo em questão, surge à iniciativa da criação de uma singela história infantil, com textos e ilustrações acessíveis sobre a doença Covid-ıg com a finalidade de propiciar uma experiência tátil sobre o conteúdo abordado, assim como para crianças com deficiência visual² (DV).

Sobre o que tange a criação do livro tátil, SOUZA E TEDERIXE (202I) explicam que é fundamental que a narrativa proporcione uma aproximação entre o texto, a imagem e o leitor. As imagens exercem uma função grandiosa no mundo imaginário dos pequenos leitores, e permitem que crianças cegas, por exemplo, sintam as ilustrações a partir da

A expressão deficiência visual ${ }^{2}(\mathrm{DV})$ refere-se às pessoas cegas e com baixa visão (visão subnormal). A perda pode ser total ou parcial, congênita ou adquirida, da visão do sujeito. (BRASIL, 20oo). 
experimentação tátil (SOUZA, SOUZA, 2020) e de acordo com ALMEIDA (2014, p.I13) a pessoa cega compensa a ausência da visão através dos sentidos remanescentes. Sobre esse aspecto, LOMÔNACO E NUNES (2010), sinalizam as possibilidades que o experimento tátil contribui para os sujeitos com deficiência visual, pois o tato possibilita o conhecimento por meio dos objetos: textura, formato, temperatura etc.

Em razão do que foi exposto anteriormente e buscando caminhar a favor da inclusão, este trabalho tem como objetivo mostrar as possibilidades e contribuições do livro tátil na formação e ensino da criança com deficiência visual frente a atual situação da crise mundial da saúde decorrente da Covid-I9.

\section{METODOLOGIA}

Este trabalho foi realizado a partir de levantamento bibliográfico e teve o seguinte percurso metodológico: a criação da história infantil sobre a doença Covid-ı́ e após publicação do livro pela editora,foi produzido a versão ampliada pelo Instituto Benjamin Constant (IBC) e uma versão tátil produzida artesanalmente pela autora.

Para a utilização prática do livro, foram realizados dois momentos de contação de história. O primeiro momento ocorreu na residência da autora com a presença e colaboração de duas crianças, sendo uma vidente com cinco anos de idade e outra com deficiência visual (cega) com nove anos de idade. O segundo momento ocorreu no salão disponibilizado pela Associação de Moradores de uma comunidade no bairro Rio Comprido, município do Rio de Janeiro. Neste segundo momento houve a participação de 29 crianças, com faixa etária entre I e II anos de idade, apenas uma com DV. Foram realizadas algumas perguntas para as crianças participantes ao início da atividade com o intuito de verificar qual o entendimento 
das mesmas sobre a crise de saúde mundial atual. Para as crianças do primeiro momento, foi solicitado que recontassem a história, objetivando estimular a imaginação, analisar a funcionalidade e contribuições do livro tátil ao participante com deficiência visual (cego).

\section{RESULTADOS E DISCUSSÃO}

\section{I Versões da história "Cora, corona"}

Pensando em contemplar o público infantil com deficiência visual (DV), a partir da versão original da história "Cora, corona”, foi produzida uma versão artesanal tátil de maneira a tornar as ilustrações acessíveis para crianças cegas, pois segundo estudos de Romani (2016), o livro tátil é entendido como um objeto multissensorial que possibilita por meio da percepção tátil a leitura por crianças com ou sem deficiência. Posteriormente foi produzido a versão ampliada (com textos e ilustrações ampliados) pelo Instituto Benjamin

Constant (IBC), localizado no bairro da Urca, na cidade do Rio de Janeiro, a fim de contemplar crianças com baixa visão. Esta versão encontra-se disponível no formato em PDF na relação de listagem de material ampliado no site do IBC<http://www.ibc.gov.br/component/content/article/2-uncategorised/rogo-livro-noformato-ampliado>. 
Figura r: imagens contendo as seis páginas ilustrativas do livro "Cora, Corona”3

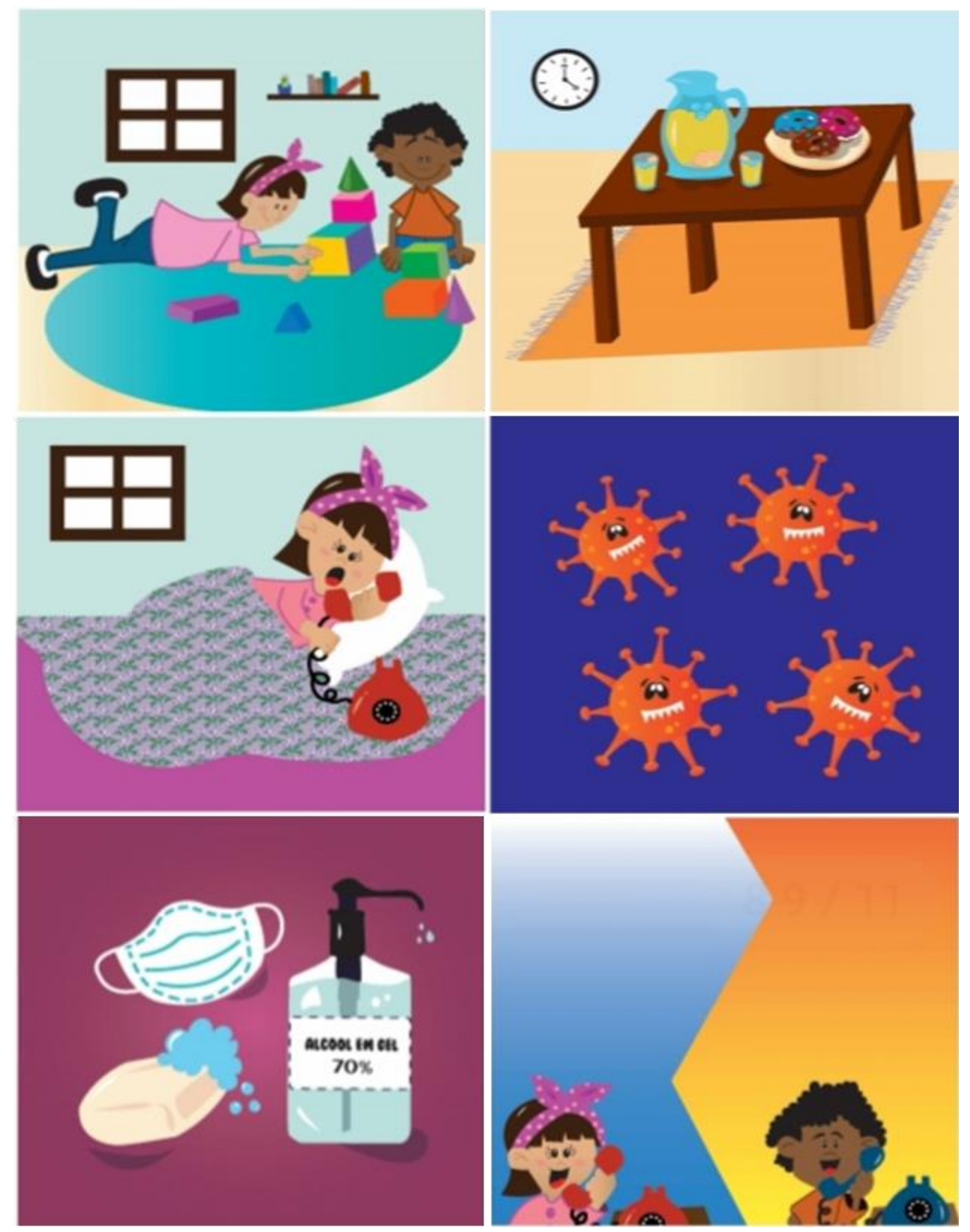

\begin{abstract}
3 Descrição das imagens. Fotor: Personagens acomodados sobre um tapete na cor azul, brincando com blocos sólidos (cone, cubos) ao fundo uma janela e ao lado direito uma pequena prateleira com alguns livros. Fotoz: Uma mesa com lanche composta de um prato com três rosquinhas, uma jarra com suco, copos e ao fundo um relógio na parede.Foto3: Personagem Cora deitada na cama falando ao telefone convencional e ao fundo uma janela .Foto4:Desenho de quatro vírus com olhos e grandes dentes na cor laranja sobre o fundo azul escuro. Foto 5:Desenho de uma máscara, um frasco escrito em seu rótulo "álcool em gel 7o \%" e um sabonete sobre um fundo de cor roxa .Foto6:Imagem da personagem Cora do lado esquerdo ao telefone convencional sobre um fundo de cor azul e ao lado direito o personagem Pedro sobre um fundo de cor alaranjado ao telefone convencional.
\end{abstract}


Quadro I": Tabela com apresentação do texto da história "Cora, corona" contendo os materiais utilizados na versão tátil em suas respectivas páginas.

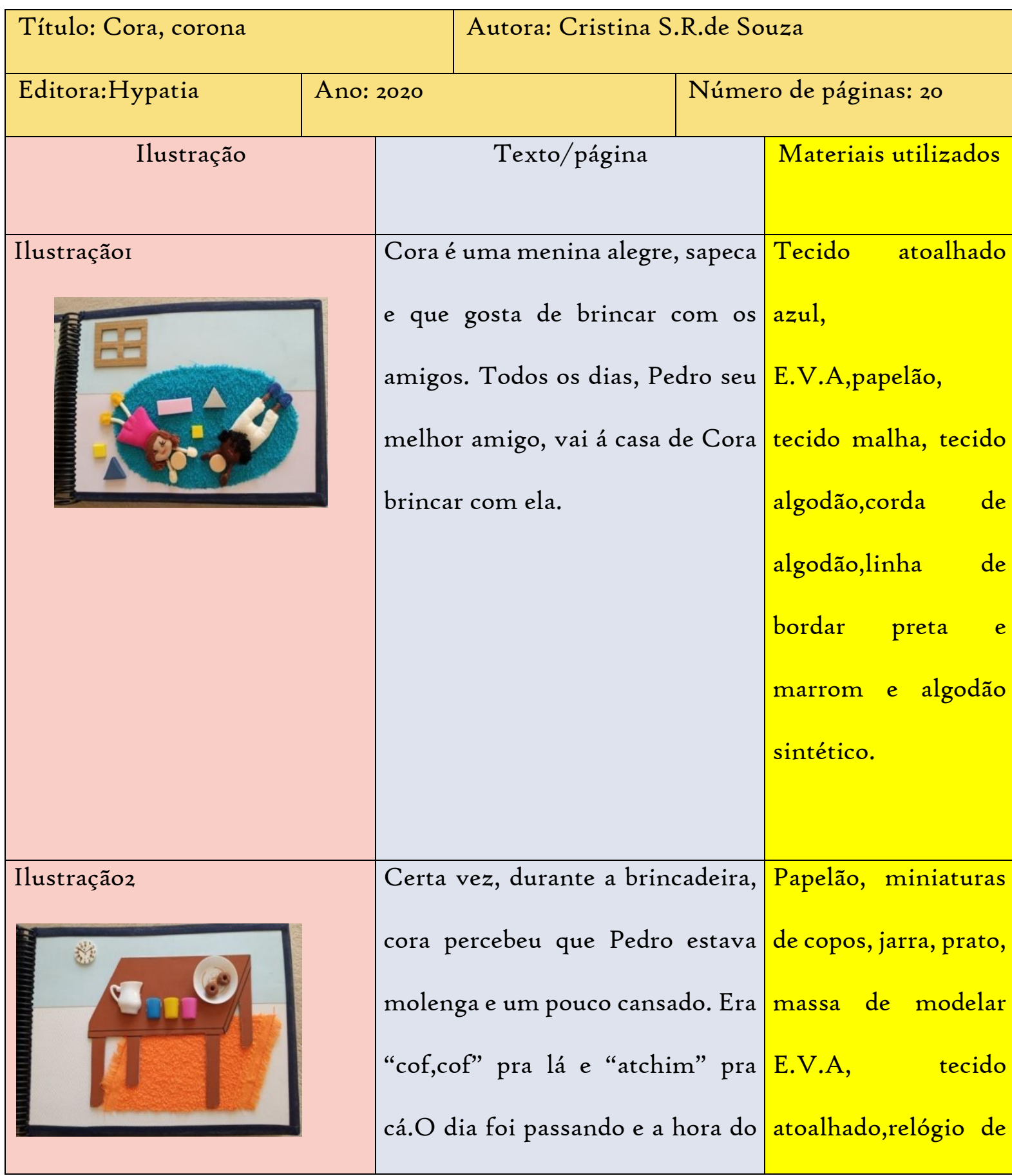

${ }_{4}^{4}$ Descrição das imagens Quadro I: O livro tátil teve todas as páginas feitas com papel paraná para que assim ficasse num formato bem rígido para o seu manuseio.Suas páginas foram fixadas em espiral e o tamanho do livro é de $21 \mathrm{~cm} \times 30 \mathrm{~cm}$. 


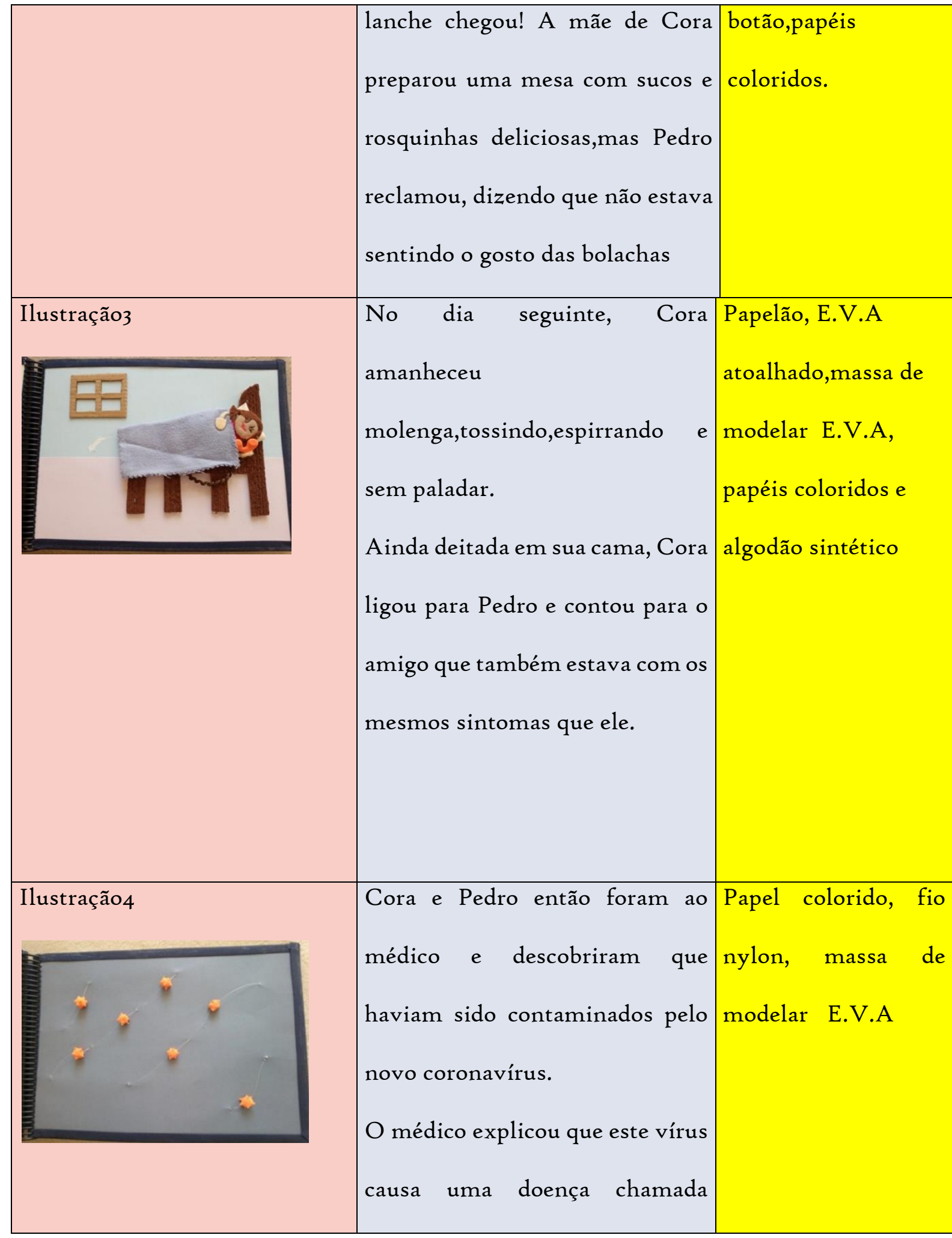




\begin{tabular}{|c|c|c|}
\hline & $\begin{array}{l}\text { Covid-ı9, que pode provocar } \\
\text { infecção respiratória. }\end{array}$ & \\
\hline Ilustraçãos & $\begin{array}{l}\text { O médico fez algumas } \\
\text { recomendações Cora e Pedro: } \\
\text { usar máscaras ao sair na rua, } \\
\text { lavar as mãos com água e sabão } \\
\text { várias vezes ao dia. Caso não } \\
\text { possam fazer uso da água e do } \\
\text { sabão, devem usar álcool em gel } \\
\text { para higienizar as mãos. E o mais } \\
\text { importante é ficar em casa } \\
\text { respeitando a quarentena e se } \\
\text { alimentar bem. }\end{array}$ & $\begin{array}{l}\text { Sache de álcool em } \\
\text { gel, máscara de } \\
\text { tecido, miniatura de } \\
\text { sabonete, papel } \\
\text { colorido, fita dupla } \\
\text { face. }\end{array}$ \\
\hline Ilustração6 & $\begin{array}{l}\text { Cora e Pedro ficaram tristes, mas } \\
\text { entenderam que o afastamento } \\
\text { era importante para a saúde de } \\
\text { todos. Sendo assim para abrandar } \\
\text { a saudade durante a quarentena, } \\
\text { Cora e Pedro tiveram a ideia de } \\
\text { continuar compartilhando as }\end{array}$ & $\begin{array}{l}\text { Tecidos de algodão, } \\
\text { tecidos de malha, } \\
\text { papéis coloridos } \\
\text { massa de modela } \\
\text { E.V.A,corda de } \\
\text { algodão e algodão } \\
\text { sintético. }\end{array}$ \\
\hline
\end{tabular}




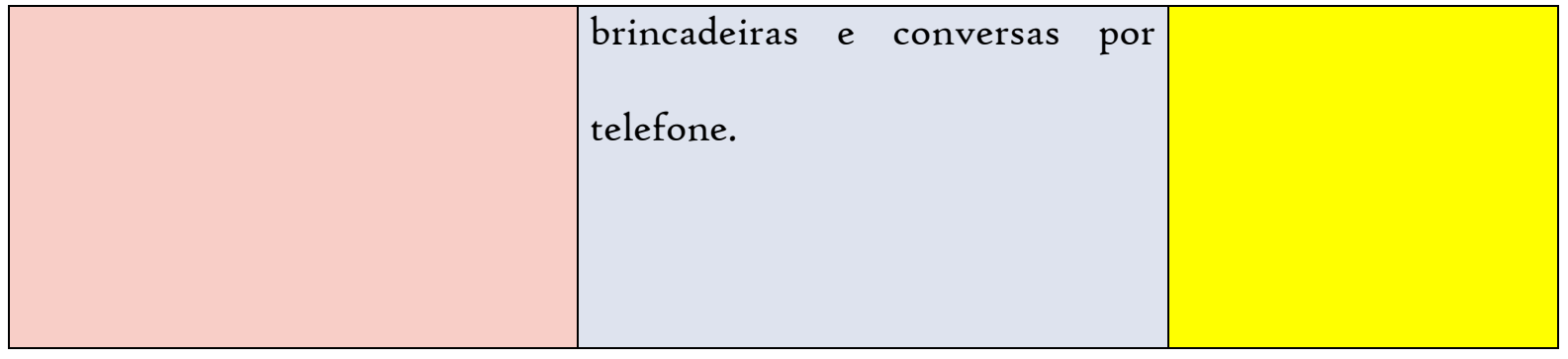

A escolha pelos materiais que compõem as ilustrações da versão do livro tátil, como por exemplo, os objetos em miniaturas, foram utilizados com o intuito de proporcionar uma leitura experimental tátil bem próximo ao real para a criança cega, a vista disso VILARONGA E SOUSA (2016) salienta que para que a ilustração seja profícua tem de ser o mais real possível.

Figura 25: capa do livro "Cora, Corona" na versão ampliada produzido pelo Instituto Benjamin Constant. Acervo pessoal.

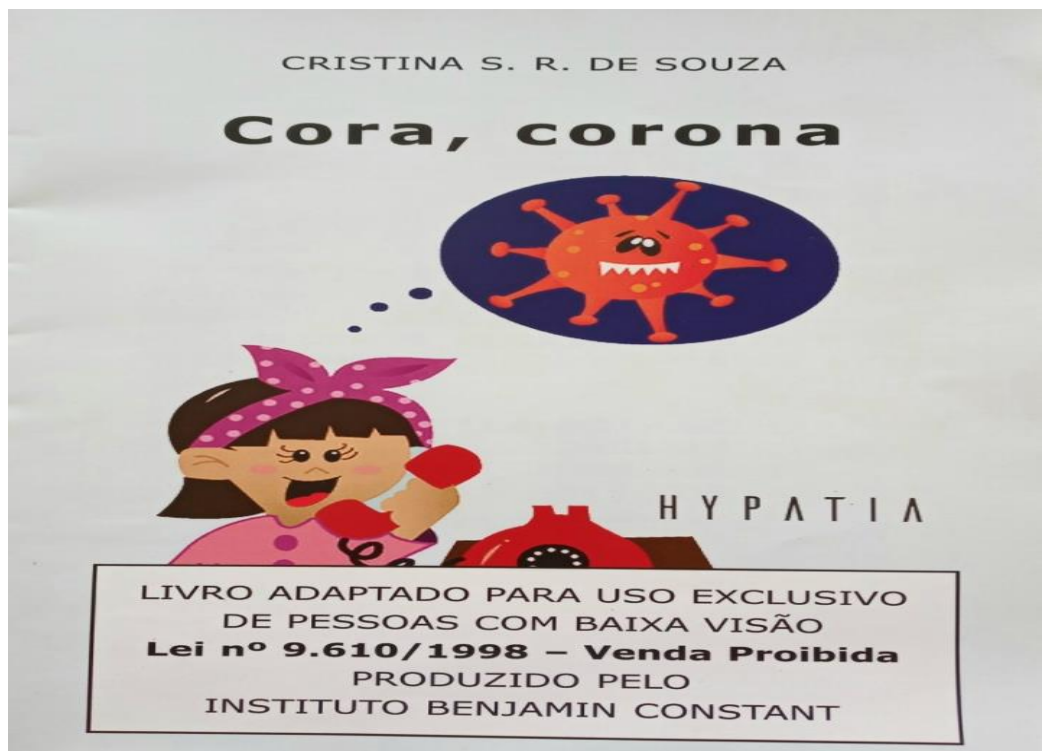

\footnotetext{
5 Descrição da figura 2: capa do livro "Cora, corona" fundo azulado, no alto da capa consta o nome da autora, mas abaixo o título da história, no meio da capa a imagem da personagem Cora ao telefone convencional e sobre sua cabeça saindo um balão de fala com a imagem do vírus. Na parte debaixo da capa está escrito: livro adaptado para uso exclusivo de pessoas com baixa visão. Lei $n^{\circ}$ 9610/1998- venda proibida. Produzido pelo Instituto Benjamin Constant.
} 


\subsection{A primeira leitura da história "Cora, corona"}

Logo que a história foi publicada pela Editora Hypatia e o livro na versão tátil ficou pronto, a narrativa foi apresentada para duas crianças na residência da autora, na ocasião, todas devidamente cumprindo os protocolos de proteção. Houve a participação de uma menina vidente, com cinco anos de idade e um menino cego de nove anos de idade, os dois acompanhados de seus respectivos responsáveis. Antes de iniciar a contação da história a autora pediu para que cada criança se apresentasse. $\mathrm{O}$ menino iniciou a apresentação com desembaraço dizendo seu nome, mas a menina demonstrou certa timidez, falando bem baixinho abraçada com sua mãe. Dando prosseguimento a autora fez algumas perguntas com o intuito de descontrair os participantes: "Vocês sabem por que estamos afastados da escola?”, "Vocês sabem qual é o nome da doença que está deixando as pessoas doentes?”, "O que temos que fazer para evitar esta doença?”.

Depois que as crianças responderam as perguntas, cada qual a sua maneira, deu-se início a contação da história. A autora optou fazer uso do livro na versão tátil, já que assim o conteúdo contido na narrativa estaria acessível tanto para menina vidente quanto para o menino cego, no mais a utilização de livro tátil e outros materiais que possibilitam a transmissão de informações por meio do tato podem alcançar êxito no processo de ensinoaprendizagem de inúmeros conteúdos (CAMARGO; NARDI, 2009; PINHO; DELOU; LIMA, 20I6; LIMA; PINHO, 20I6; ROCHA; SILVA, 2016). Portanto, sendo o livro infantil uma ferramenta de fonte de conhecimentos, a opção pelo livro tátil também se fez pela sua representação acessível, interativa e lúdica. 
Antes de começar a leitura propriamente dita, foi feito uma apresentação do título da história, foi falado os nomes de quem escreveu (o autor) e de quem fez as imagens/desenhos (o ilustrador) do livro. Pronto! Hora de começar e eis que surgem as três palavrinhas mágicas, Era uma vez...

Dando início a leitura do livro, a autora a cada página lida mostrava as ilustrações para a menina e em seguida colocava o livro na mão do menino para que o mesmo pudesse interagir, tatear e "ver com as mãos" a imagem que compunha a cada página que era folheada. Foi observado que diante esses momentos de interação e toque no livro o menino mostrou-se bastante participativo, curioso, não apresentou nenhuma aversão e a experiência com o objeto foi bastante válido. A sensação prazerosa demonstrada pelo menino ao tocar o "vírus", (feito com massa de modelar E.V.A), por exemplo, foi de fato surpreendente vê-lo tateando sorridente e dizendo: "Olha o coronavírus! E foi assim que a contação da história transcorreu aos olhos da menina vidente a nas mãos do menino cego.

Ao findar a contação da história cada criança foi presenteada com o livro e levaram para casa. A autora sugeriu e incentivou que cada uma das crianças (re)contasse a história para suas famílias. $\mathrm{O}$ ato de recontar uma história é fundamental para que a criança amplie possibilidades imaginárias e crie um vínculo precioso entre o narrador e o ouvinte (CARDOSO e FARIA, 2009). Faz-se importante destacar que os benefícios do reconto de uma narrativa são muito rico e mágico para a criança e muito contribui no seu desenvolvimento social e contempla diversas áreas do conhecimento.

Alguns dias depois as mães das crianças participantes enviaram fotos e vídeos mostrando como foi a contação da história em casa. A menina vidente, ainda não 
alfabetizada, foi filmada pela mãe sentada no sofá de sua casa, folheando o livro e à medida que ia virando a página olhava as imagens e narrava a história a sua maneira. Sobre isso, ARIDE (2015) explica que ainda que a criança não se encontre familiarizada com o texto verbal, por meio das ilustrações, elas são capazes de identificar e compreender situações do texto/conteúdo apresentado. Era muito perceptível ver isso na filmagem, pois em alguns momentos a menina fixava o seu olhar por mais tempo nas ilustrações de determinada página e em seguida oralizava com espontaneidade a sua "leitura" imaginária. Sobre isso, ALMEIDA (2014, p.9I) contribui dizendo que o imaginário da criança precisa ser enriquecido para que ela possa engrandecer a realidade que está a sua volta. Por certo a magia e o encantamento das histórias infantis favorecem o imaginário do sujeito.

Finalizando a contação da narrativa, a menina desejou realizar um desenho sobre a história, à mãe fotografou e compartilhou com a autora.

Figura $3^{6}$ :Desenho da menina sobre a história. Acervo pessoal.

Sobre a experiência do menino cego alfabetizado, ele aparece nas filmagens sentado no chão de sua casa contando a história para uma prima (detalhes revelados pela mãe). Antes

\footnotetext{
${ }^{6}$ Descrição da imagem: Foto da menina segurando com as duas mãos o seu desenho feitona folha com o cenário
} de vários "vírus" e os personagens da história. 
de abrir o livro, o menino tateou a capa e pegou a mão da prima e de sua mãe para tatear a escrita do título da história em Braille e no decorrer da sua leitura nas demais páginas, novamente tateou as imagens e os textos em Braille junto a sua prima, como ilustram as fotos a seguir.

Figura $4^{7}$ : menino tateando o livro tátil.
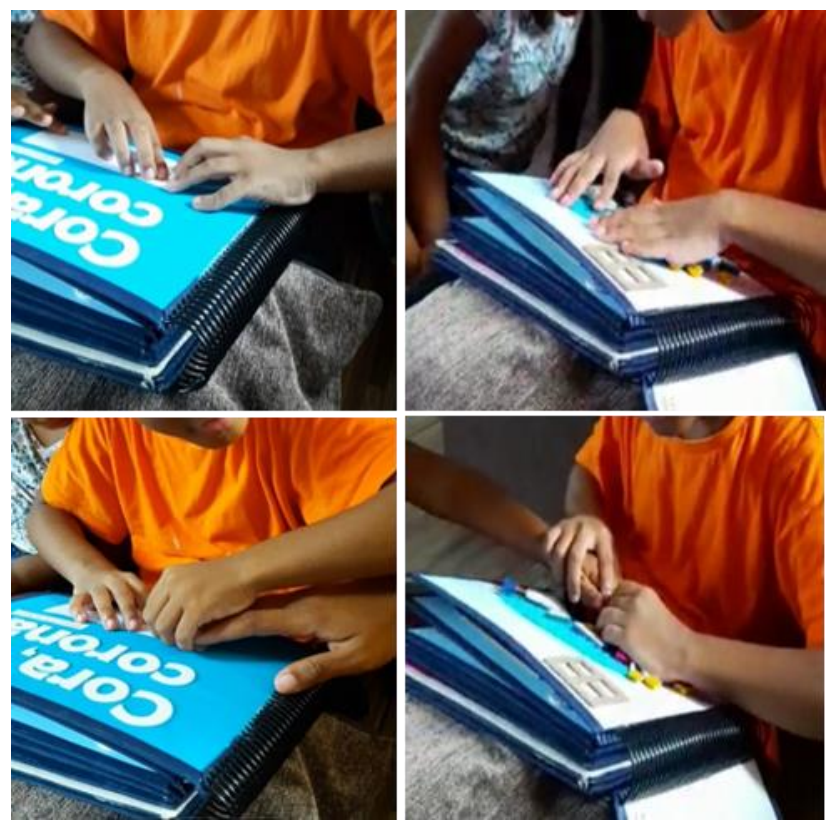

Era possível observar na filmagem que ao folhear e tatear as páginas do livro, o menino se atentava aos detalhes dos elementos de cada cena, como por exemplo, as miniaturas dos copos plásticos, os cabelos dos personagens, e essa experiência tátil o auxiliou a recontar à narrativa e entender a ilustração que correspondia a página lida. Ao mesmo tempo em que recontava a história o menino pegava na mão da prima e junto com ela tateava a ilustração para que ela também percebesse que aquela imagem correspondia a sua leitura. Foi possível observar que o menino foi capaz de dar sequência aos fatos da narrativa e que

\footnotetext{
7 Descrição da imagem: quatro fotos do menino tateando a escrita Braille do título da história e a ilustração da primeira página do livro.
} 
as ilustrações táteis em cada página do livro foi o alimento ativador para sua imaginação. Diante tal exploração tátil é percebido que o experimento do menino cego sobre o livro tátil lhe proporcionava conhecimentos por meio das texturas e formatos correspondentes a ilustração (LOMÔNACO\& NUNES, 2010). Em concordância com os autores, a experiência com LT viabilizou a criança o reconto da narrativa sem a perda do contexto da história.

\subsection{Segunda leitura: A história “"Cora, corona" vai à comunidade}

A segunda leitura é um desdobramento em decorrência da primeira experiência, pois a partir disso o responsável do menino entrou em contato com a autora convidando-a a levar a história para sua comunidade localizada no bairro do Rio Comprido, na cidade do Rio de Janeiro.

Em razões das restrições, por conta da pandemia, para não aglomerar crianças e responsáveis, foi realizado primeiro uma pesquisa sobre o quantitativo de crianças que iriam participar da contação da história. Após isso, se pensou em formalizar o evento através de um convite virtual que foi enviado via aplicativo de mensagens para as famílias.

Para que a condução desta ação literária contemplasse todas as crianças foi importante pesquisar o quantitativo de crianças participantes (CP), a faixa etária e verificar se havia criança participante com alguma deficiência. Diante disso, firmou-se que eram 29 crianças, com faixa etária entre I ano e Iranos de idade,sendo uma criança cega(o mesmo menino que participou da primeira experiência). Para obedecer a regra de distanciamento social com esse quantitativo de crianças, dividiu-se em dois grupos: um primeiro grupo com 
I5 crianças e o segundo grupo com 14 crianças. Foram feitos dois convites, com horários diferentes e enviados para seus respectivos grupos via aplicativo de mensagem.

Figura $5^{8}:$ imagem dos convites que foram enviados para as famílias. Acervo pessoal
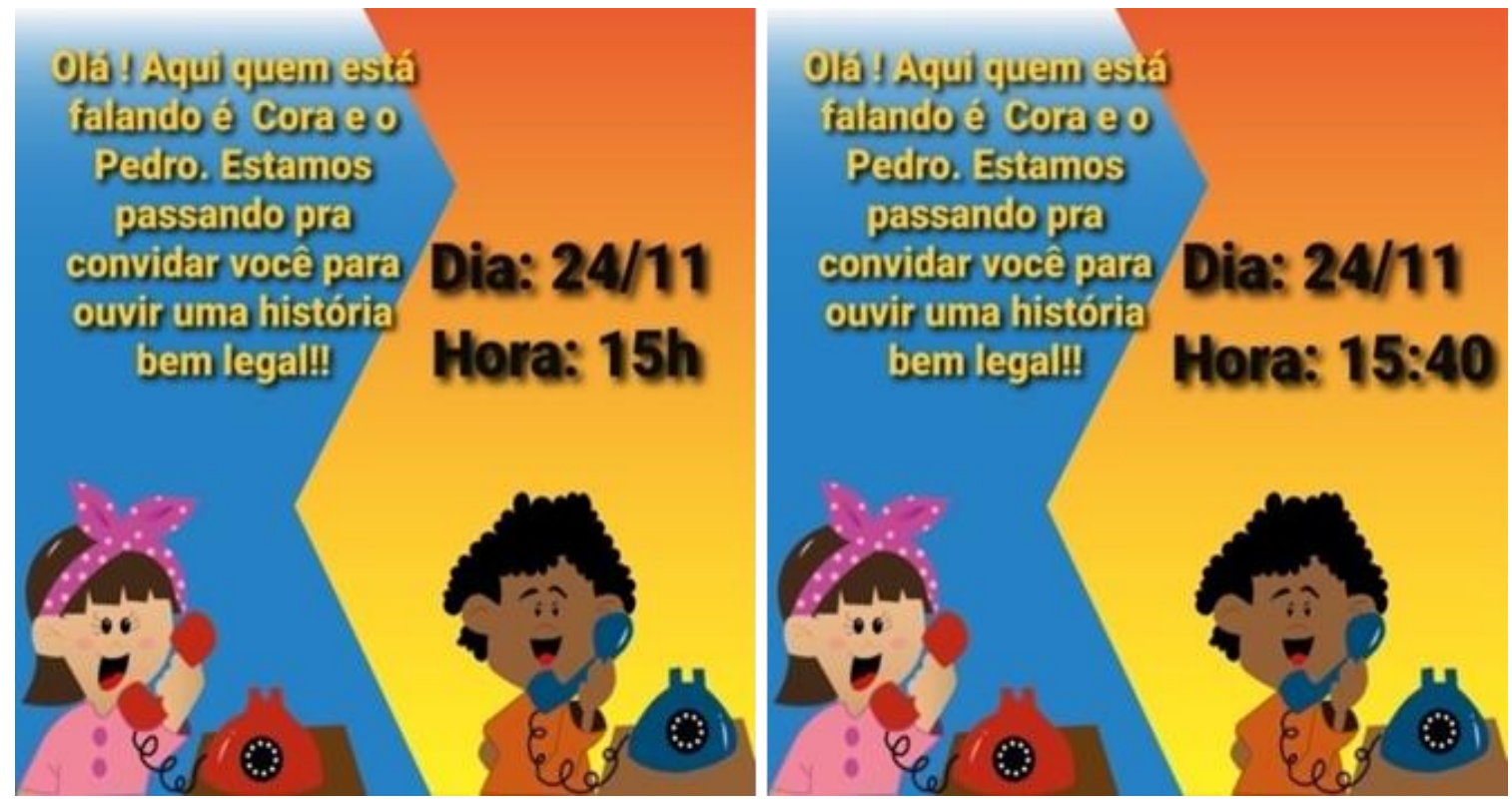

O espaço oferecido pela comunidade para a realização da contação de história foi a

associação de moradores.

Para iniciar a contação da história, antes da chegada das crianças, a autora preparou o local fixando no chão à quantidade de círculos em TNT (tecido não tecido) correspondente a quantidade de participantes, com o propósito de marcar os lugares que cada criança iria sentar objetivando respeitar o distanciamento. Foi disponibilizado álcool em gel para que todos fizessem a higienização das mãos ao entrarem no espaço durante toda permanência no local e cada criança foi presenteada com uma máscara de tecido.

\footnotetext{
${ }^{8}$ Descrição das imagens: Imagens dos dois convites ambos contendo a personagem Cora do lado esquerdo ao telefone convencional sobre um fundo de cor azul e ao lado direito o personagem Pedro sobre um fundo de cor alaranjado ao telefone convencional e em cada convite está escrito data, hora e o seguinte texto: Ólá! Aqui quem está falando é a Cora e o Pedro. Estamos passando pra convidar você para ouvir uma história bem legal!!
} 
Era uma vez...

Contar histórias é uma arte, pois requer artifícios para conquistar a atenção dos ouvintes. É preciso despertar e fomentar o imaginário dos pequeninos de maneira a levá-los a relacionar o conteúdo da história com o mundo que a cerca (ABRAMOVICH, 1995, p.17),

Para tanto, a fim de tornar a história atraente aos pequenos leitores, a autora também deu vida aos principais personagens da história, "Cora e Pedro", produzindo-os em um formato de fantoches.

Figura: 69: bonecos fantoches dos personagens da história (Cora e Pedro) utilizados na contação de história. Acervo pessoal.

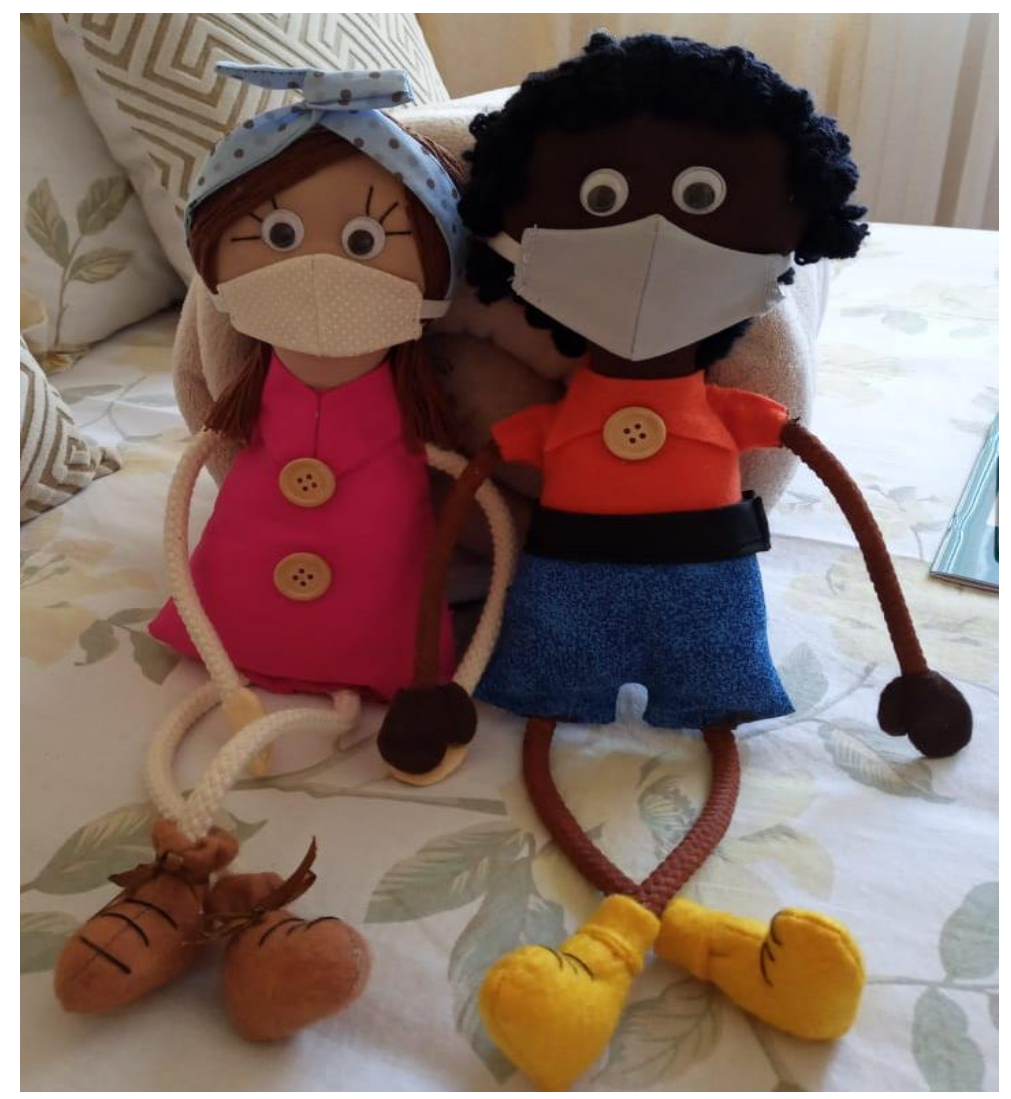

\footnotetext{
9 Descrição da imagem: foto dos bonecos fantoches Cora e Pedro sentados um ao lado do outro com as pernas cruzadas e ambos com máscaras de proteção.
} 
No momento em que os fantoches chegam às mãos do menino cego, ele extravasa alegria, e é percebido o quanto ele se atenta as características dos bonecos também, como por exemplo, o tipo de cabelo de cada personagem, as roupas, e o menino compara as máscaras que estavam no rosto dos bonecos com a dele. É importante destacar que o menino cego tem o mesmo nome do personagem da história e isso fez com que ele se identificasse com o personagem por uma questão de identidade (nomes iguais). Nesta parte de apresentação dos personagens, o menino cego enfatizou "O nome dele é igual ao meu!"

Percebeu-se até aqui, que o início e a introdução foram estimulantes, oportunizou a interação de todos e funcionou como um bom combustível. A curiosidade e a imaginação de cada um estavam a todo vapor.

Feito toda essa introdução, com o intuito de verificar qual o entendimento dos espectadores sobre a doença e o isolamento, assim como na primeira leitura, na segunda leitura antes de iniciar a contação da história, a autora fez as mesmas perguntas para as CP dos dois grupos: "Vocês sabem por que estamos afastados da escola?", "Vocês sabem qual é o nome da doença que está deixando as pessoas doentes?", "O que temos que fazer para evitar esta doença?”. A maioria, prontamente com as mãos levantadas, dissera o nome da doença e o que se deve fazer para evitá-la: “usar máscara!” / lavar as mãos!” / usar álcool gel!”, “ficar em casa!”. Esse foi o ponto de partida para apresentar e dar início à leitura do livro. A partir desta euforia a autora deu início a contação da história cantando a canção...

\footnotetext{
"Ouvi contar uma história,

Uma história engraçadinha,

do coronavírus quem ouviu,

do coronavírus quem ouviu?”
} 
Considerando as contribuições de LOMÔNACO E NUNES (2010), onde os mesmos afirmam que o experimento tátil muito contribui para os sujeitos com deficiência visual e lhe permite o processamento das informações que lhe são apresentadas, foi veemente importante que o menino cego ficasse acomodado junto a autora, pois era de extrema magnitude que ele estivesse próximo para que a medida que ia sendo feito a leitura do livro o mesmo pudesse realizar o experimento tátil das imagens que compunha a cena do momento. Apesar de já ter conhecido o livro na primeira contação, todas as vezes que a autora levava o livro até as mãos do menino cego, o mesmo tateava as ilustrações com entusiasmo, curiosidade e com uma imaginação bastante aflorada.

Sobre isso ABRAMOVICH (1995) corrobora dizendo que é a partir da contação de histórias que a criança fomenta seu imaginário, sendo capaz de associar o que escuta com a realidade e dessa forma consegue entender suas ações em relação ao outro, com o mundo ao seu redor e enfrentar situações difíceis.

Após o término da história a autora explorou o conteúdo da narrativa dialogando com os participantes sobre o motivo pelo qual foram necessárias as escolas fecharem, o porquê do isolamento e o quanto é importante evitar aglomerações. Rememorou as recomendações que o médico fez aos personagens da narrativa e o quanto é importante que façamos o mesmo: lavar as mãos com água e sabão ou higienizá-las com álcool gel sempre que possível.

\section{CONCLUSÃO}

A criança com DV não se diferencia da criança vidente em essência, pois ambas possuem ideias, elaboram conceitos, mas o que diferencia uma da outra são as experiências 
e o grau de oportunidades que cada uma recebe (ALMEIDA, p.II2). Levar a criança cega a manipular, explorar o mundo ao seu redor é oportunizar e possibilitar para ela um aprendizado sólido e significativo.

Alicerçado nos resultados narrados, o presente estudo desenvolvido, mostrou a relevância que se tem a criação e produção do livro infantil tátil, onde crianças com deficiência visual possam manusear ler e compreender as informações contidas na narrativa. Foi percebido nas experiências vividas pelo participante com DV, que o livro tátil oportunizou condições favoráveis no manuseio, compreensão da narrativa e do seu conteúdo apresentado. Através da contação da história e a aplicabilidade do livro tátil foi observado o quanto este recurso viabilizou experiências sensoriais ao pequeno leitor cego diante as ilustrações táteis contidas no livro e sua interação com a narrativa e demais colegas.

\section{REFERÊNCIAS BIBLIOGRÁFICAS}

ABRAMOVICH, F. Literatura Infantil: gostosuras e bobices. $5^{\circ}$ edição. São Paulo: Editora Scipione,1995.

ALVAREZ, M.\& CORTÉS, E. Aprender a ver, aprender a tocar. Integración, n. 33, p. 2025, 2000.

ARIDE, A. de S. Design Inclusivo: livro ilustrado multissensorial para crianças deficientes visuais e videntes. Rio de Janeiro: Universidade Federal do Rio de Janeiro, 2015. II2 f. Trabalho de Conclusão de Curso.

BRASIL. Deficiência visual / Marta Gil (org.). - Brasília: MEC. Secretaria de Educação a Distância, 2000. 8o p.: il. - (Cadernos da TV Escola. I. ISSN I518-4692) 
BRASIL. Ministério da Saúde. Como se proteger?Disponível em<https://www.gov.br/saude/pt-br/coronavirus/como-se-proteger >. Acesso em:

CAMARGO, E. P. \& NARDI, R. Inclusão no ensino de física: materiais e metodologia adequados ao ensino de alunos com e sem deficiência visual. In: R. NARDI, (Org). Ensino de ciências e matemática I: temas sobre a formação de professores [online]. São Paulo: Editora UNESP, São Paulo: Cultura Acadêmica.20o9.

CARDOSO, Ana Lúcia Sanches; FARIA, Moacir Alves de. A Contação de Histórias no Desenvolvimento da Educação Infantil. FAC/São Roque, 2009.

FONSECA, V. Perturbações do desenvolvimento e da aprendizagem: Tendências filogenéticas e ontogenéticas. Lisboa: Edições FMH, 1999.

GARCIA, W. \& GARCIA, O. Baú do Professor. Belo Horizonte: FAPI, 2003.

KAERCHER, G. E. P. da S. E Por Falar em Literatura. In: CRAIDY, C. M. \& KAERCHER, 856 G. E. P. da S. Educação infantil: pra que te quero? Porto Alegre: Artmed, 20oI.

LOMÔNACO, J. F. B.\& NUNES, S. da S. Desenvolvimento de conceitos em cegos congênitos: caminhos de aquisição do conhecimento. Psicologia Escolar e Educacional, Campinas, v. I2, n. I, p. I19-138, jun. 2008.

MENEZES, J.A.et al. A contação de histórias no Instagram como tecnologia leve em tempos pesados de pandemia. Psicologia \& Sociedade, v. 32, 2020.

PEREIRA, F. Educação especial: Manual de apoio à prática. Lisboa: DGIDC, 2008a PEREIRA, F. Alunos cegos e com baixa visão: Orientações curriculares. Lisboa: DGIDC, $2008 \mathrm{~b}$. 
PINHO, T. M. M., Delou, C. M. C., \& Lima, N. R. W. (2or6). Origami as a tool to teach geometry for blind students. Creative Education, 7(17), 2652-2665.

PINHO, T. M. M., \& LIMA, N. R. W. (2016). Dobrando sacolas de plástico: Um instrumento no ensino de geometria para estudantes cegos do ensino fundamental Natal, RN. Anais do III Congresso Brasileiro de Educação. Acesso 2I nov., 2018. http://www.editorarealize.com.br/revistas/conedu/trabalhos/TRABALHO_EVo56_MDI _SA7_ID3 827_I4082016003230.pdf .

ROCHA, S. J. M., \& SILVA, E. P. (2016). Cegos e aprendizagem de genética em sala de aula: percepções de professores e alunos. Revista Brasileira de Educação Especial, 22(4),589604.

ROMANI, E. (2016). Design do livro tátil ilustrado: processo de criação centrado no leitor com deficiência visual e nas técnicas de produção gráfica da imagem e do texto. São Paulo, 246 p: il. Tese (Doutorado em Design e Arquitetura) Faculdade de Arquitetura e Urbanismo, USP.

SOUZA, Cristina Silva Ribeiro de, SOUZA, Sylvia Soares de. A importância da ilustração tátil tridimensional nas histórias infantis para os alunos cegos. XX Endipe. Rio de Janeiro, 2020 - Fazeres-Saberes Pedagógicos: diálogos, insurgências e políticas.

TEDERIXE, Lisania Cardoso, SOUZA, Cristina Silva Ribeiro de Oficina de livro tátil: uma proposta de capacitação de professores por meio do ensino remoto durante a pandemia. Revista Ibero-Americana de Humanidades, Ciências e Educação-REASE.v.7 n.8.202I.

VILARONGA, Rosane Souza; SOUZA, Olenêva Sanches. A Ilustração Tátil na Contação de História: o Programa Etnomatemática e o Imaginário a Criança Cega. v. 9, n.I, 2016. 


\section{Disponível}

em:<https://eventos.set.edu.br/index.php/enfope/article/view/224I/657>Acessado em 04 de outubro de 2021. 